Revista de Filología Románica

ISSN: 0212-999X

http://dx.doi.org/10.5209/RFRM.58356

\title{
La propia casa como espacio hostil para dos heroínas de Cervantes
}

\author{
Lavinia Similaru $^{1}$
}

Recibido: 10 de diciembre de 2016 / Aceptado: 20 de julio de 2017

Resumen. La falta de libertad convierte hasta la propia casa en un espacio hostil. Dos heroínas de Cervantes -Lorenza, la protagonista del entremes «El viejo celoso», y Leonora, la protagonista de la novela ejemplar «El celoso extremeño»-, perciben sus casas como un espacio hostil, ya que viven encerradas peor que en una cárcel, por los celos de sus maridos. Les falta la libertad.

Palabras clave: Cervantes; libertad; mujeres; casa; figuras de estilo.

\section{[en] The house itself as a hostile space for two of Cervantes' heroines}

\begin{abstract}
The lack of liberty turns even your own home into a hostile space. Two of Cervantes' heroines, Lorenza, the protagonist of the entremés "The Jealous Old Man" and Leonora, the protagonist of the exemplary novel "The Jealous Extremaduran"-, perceive their homes as a hostile space, since they live locked up worse than in a prison, by the jealousy of their husbands.

Key words: Cervantes; freedom; women; home; figures of speech.
\end{abstract}

Sumario. 1. Actualidad de Cervantes. 2. Realismo, valor histórico y documental de las obras de Cervantes. 3. Cervantes y la libertad. 4. Cervantes y el matrimonio. 5. La casa como espacio hostil para las dos heroínas. 5.1. Lorenza. 5.2. Leonora. 6. Referencias bibliográficas.

Cómo citar: Similaru, L. (2017). La propia casa como espacio hostil para dos heroínas de Cervantes, en Revista de Filología Románica 34.2, 361-369.

\section{Actualidad de Cervantes}

Según escribe Víctor Ivanovici en su interesantísimo libro Itinerarios cervantinos, «las despedidas de las grandes obras de la humanidad no son sino rodeos que nos traen de vuelta a ellas» (Ivanovici 2016: 12). Don Quijote y las demás obras de Cervantes forman, sin duda, parte de este tipo de obras. Han pasado más de 400 años de la muerte del ilustre escritor, pero seguimos leyendo sus obras. El Caballero de la Triste Figura tiene el inmenso mérito de inspirarnos y de animarnos a cada uno

\footnotetext{
1 Universitatea din Craiova, România lavinia_similaru@yahoo.es
} 
de nosotros, empujándonos a conocernos mejor a nosotros mismos, y a explorar sin temores nuestras entrañables ansias y angustias inconfesables. Nos hace gestionar mejor nuestros sueños inalcanzables, y acabar aceptando nuestros inevitables límites, ya que vencernos a nosotros mismos es la mayor victoria. Por eso, la humanidad ha necesitado y necesita, y necesitará siempre a Don Quijote. Don Francisco Rico observaba que «Cervantes estaba lejos de tener y decir la última palabra. El Quijote dice muchas cosas, pero hay muchas más que no niega, e infinitas que sugiere» (Rico 2012: 137). Don Francisco Rico no se equivoca: a lo largo de los siglos, en los momentos más difíciles y más perturbadores, los españoles o, mejor dicho, la humanidad entera ha tenido que volver a pensar en don Quijote, para que el caballero le diera el valor que necesitaba para encontrarse a sí misma. Más de cien años han pasado desde que Miguel de Unamuno le evocaba en unas antológicas líneas, destacando y deplorando la miseria de la vida cotidiana, y recordando que el caballero nos da «el valor que más falta nos hace: el de afrontar el ridículo. El ridículo es el arma que manejan todos los miserables bachilleres, barberos, curas, canónigos y duques que guardan escondido el sepulcro del Caballero de la Locura» (Unamuno 1992: 140).

El 23 de abril de 2015 -año del cuadricentenario de la Segunda Parte del Quijote-, el escritor Juan Goytisolo, laureado con el Premio Cervantes, destacaba en su discurso que los seres humanos de nuestra época sienten la necesidad de leer a Cervantes, y que don Quijote sigue siendo un modelo para los seres humanos del siglo XXI, ya que la sociedad contemporánea es igual de injusta que en los tiempos del Caballero, y a nosotros también nos cuesta aceptarlo.

A su vez, Eduardo Mendoza, al recibir el mismo premio Cervantes, se declaraba en 2017 lector y discípulo de Cervantes.

\section{Realismo, valor histórico y documental de las obras de Cervantes}

Más allá de su valor simbólico, Don Quijote y las demás obras de Cervantes ofrecen una imagen inesperadamente realista del mundo contemporáneo, constituyendo en la actualidad, cuatro siglos después de su publicación, un valiosísimo y asombroso documento histórico. El mundo del Quijote, de las novelas ejemplares, de los entremeses está poblado por gente del pueblo y gente acomodada, nobles, curas, frailes, barberos, venteros, pastores, labradores, titiriteros, ladrones, bandoleros, fregonas y mujeres vulgares... Todos retratados con un realismo admirable. Jean Canavaggio destaca:

Resucitar la caballería andante es encarnarla en la cotidianidad, en el marco familiar de una existencia concreta: las llanuras de la Mancha adonde el héroe va en busca de aventuras, la venta donde es armado caballero, los caminos por los que se cruza con cabreros, monjes y galeotes sólo muestran el «realismo» cervantino como signos de un presente del que no podría abstraerse y que, en la cúspide de su exaltación, lo devuelve siempre a la tierra. En la bisagra del mundo prosaico en el que se arraiga y del mundo ideal hacia el que se proyecta incansablemente, don Quijote no tiene más salida que integrar este presente en su sistema de pensamiento (Canavaggio 1995: III 62). 
Toda la obra de Cervantes constituye una inagotable fuente de informaciones históricas sobre su época. No podemos dejar de recordar las palabras de Ángel del Río:

... hasta en un plano tan aparentemente real, de literatura costumbrista, como el de los entremeses, encontramos ese doble fondo permanente de la visión genial de Cervantes: la disonancia y armonía entre vida y poesía; entre el mundo necesario, condicionado, de las realidades materiales y el mundo libre, arbitrario, de la imaginación. En el descubrimiento de la interrelación entre esos mundos y en haber sabido dar plasticidad artística a ese descubrimiento consiste la gran invención de Cervantes. (Río 1982: I 474).

Dos heroínas de Cervantes -Lorenza, la protagonista del entremés El viejo celoso, y Leonora, la protagonista de la novela ejemplar El celoso extremeño-, son mujeres comunes y corrientes de la época de Cervantes. Ellas llegan a percibir sus propias casas como un espacio hostil, ya que viven encerradas peor que en una cárcel, por los celos de sus maridos. Están casadas con hombres mayores que ellas, y les falta la libertad. Los matrimonios inadecuados, entre contrayentes de edades diferentes, y la libertad son dos temas gratos a Cervantes, temas que confluyen en el entremés $E l$ viejo celoso y en la novela ejemplar El celoso extremeño, provocando el drama de las protagonistas. Son asimismo dos de los problemas planteados por la sociedad y por la literatura de la época.

\section{Cervantes y la libertad}

Francisco Javier Díez de Revenga cita las palabras de Cervantes mismo, asegurando que el gran escritor del Siglo de Oro «supo valorar, como nadie, el bien más grande que existe, la libertad, uno de los más preciosos dones que a los hombres dieron los cielos ...». (Díez de Revenga 2016: 15).

Es innegable el interés de Cervantes por la libertad; sus obras son un canto a la libertad. No podemos dejar de recordar un episodio sugestivo de la vida del escritor: en 1575, después de haber participado en la batalla de Lepanto (1571), y en otras campañas, Miguel de Cervantes se embarcó en Nápoles en la galera Sol para ir a España. Pero cerca de Marsella la galera en que navegaban fue atacada por tres naves turcas, y los españoles tuvieron que rendirse. El escritor y su hermano Rodrigo fueron llevados presos a Argel. En los temidos baños de Argel, que describirá tantas veces en sus obras, pasará Cervantes los próximos cinco años y medio de su vida. Son años muy duros, aguantados con resignación, años durante los cuales «aprendió a tener paciencia en las adversidades», como nos confiesa en el prólogo de las Novelas ejemplares (Cervantes 1992: 51). Cuatro veces trató de evadirse, arriesgando su vida, y tratando de salvar a los demás, pero sus intentos fallaron. Los años de cautiverio serán evocados con una noble melancolía y sin rencores en las obras de teatro, en la historia del Cautivo del Quijote, en El amante liberal, o en La española inglesa.

Son inolvidables las palabras de Ricardo, protagonista de la novela ejemplar $E l$ amante liberal: «...la perdida libertad, por quien mis ojos han derramado, derraman y derramarán lágrimas sin cuento, y la por quien mis sospiros encienden el aire cerca 
y lejos, y la por quien mis razones cansan al cielo que las escucha y a los oídos que las oyen...» (Cervantes 1992: 142).

Don Quijote le dice a Sancho, en el capítulo LVIII de la Segunda parte:

La libertad, Sancho, es uno de los más preciosos dones que a los hombres dieron los cielos; con ella no pueden igualarse los tesoros que encierra la tierra ni el mar encubre; por la libertad, así como por la honra, se puede y debe aventurar la vida, $\mathrm{y}$, por el contrario, el cautiverio es el mayor mal que puede venir a los hombres (Cervantes 2001: II 1338).

En los capítulos 12 - 14 de la Primera parte de Don Quijote, Marcela es un personaje que reivindica su libertad, negándose a casarse, puesto que «no se sentía hábil para poder llevar la carga del matrimonio» (Cervantes 2001: I 165). El autor nos cuenta que «Marcela se puso en aquella libertad y vida tan suelta y de tan poco o de ningún recogimiento» (Cervantes 2001: I 166). En la época, la alternativa de cualquier mujer era el matrimonio o el convento. Marcela rechaza estos dos destinos, quiere ser libre, según declara: «Yo nací libre, y para poder vivir libre escogí la soledad de los campos» (Cervantes 2001: I 193). Más adelante, reitera su deseo de libertad: «tengo libre condición y no gusto de sujetarme» (Cervantes 2001: I 195).

Como subraya J. Ignacio Díez Fernández, «la libertad que defiende Marcela [...] equivaldría casi a una vida en soledad, elegida conscientemente» (Diez Fernández 2004: 1265).

\section{Cervantes y el matrimonio}

Puesto que Cervantes nunca evocó a su esposa en sus obras, o no lo hizo abiertamente, y los lectores no han sabido desentrañar las huellas de doña Catalina, se supone comúnmente que su matrimonio fue infeliz. Pero no hay ninguna certeza. De todos modos, no hay duda de que el tema del matrimonio preocupaba mucho a Cervantes, es un tema que se puede rastrear a lo largo de todas sus obras. De los ocho entremeses, solamente tres no tienen relación con este tema: La elección de los alcaldes de Daganzo, El vizcaíno fingido, y El retablo de las maravillas. Todos los demás entremeses - El juez de los divorcios, El rufián viudo, La guarda cuidadosa, La cueva de Salamanca y El viejo celoso - plantean, de una forma u otra, el problema del matrimonio. De las doce novelas ejemplares, solo tres no están relacionadas con el tema del matrimonio: Rinconete y Cortadillo, El licenciado Vidriera, y El coloquio de los perros. En todas sus novelas aparecen parejas casadas, o que aspiran a casarse.

A veces, el autor nos asegura que alguna de las parejas vive feliz hasta la muerte, como es el caso de Rodolfo y Leocadia, protagonistas de la novela ejemplar $L a$ fuerza de la sangre, que al final parecen vivir un cuento de hadas:

Llegóse, en fin, la hora deseada, porque no hay fin que no le tenga. Fuéronse a acostar todos, quedó toda la casa sepultada en silencio, en el cual no quedará la verdad deste cuento, pues no lo consentirán los muchos hijos y la ilustre descendencia que en Toledo dejaron, y agora viven, estos dos venturosos desposados, que 
muchos y felices años gozaron de sí mismos, de sus hijos y de sus nietos, permitido todo por el cielo y por la fuerza de la sangre, que vio derramada en el suelo el valeroso, ilustre y cristiano abuelo de Luisico (Cervantes 1994: II 95).

Pero los Entremeses nos muestran que Cervantes tenía generalmente una visión mucho más realista, y a veces hasta pesimista sobre el matrimonio, y destacaba una serie de problemas matrimoniales, frecuentes en su época: los celos enfermizos del marido viejo (tal vez provocados por la impotencia) y de aquí la falta de concordia entre un marido viejo y una mujer joven; la escasez de recursos económicos, que acarrea el disgusto de la mujer, a quien el marido no puede mantener y ofrecer el modo de vida que ella desearía; y el adulterio de la mujer, en cuyas causas o justificaciones el escritor no suele ahondar.

Son inolvidables las palabras de Mariana en el entremés El juez de los divorcios, la mujer critica el matrimonio que dura toda la vida, lo que resulta asombroso para la época de Cervantes, ya que el punto de vista de Mariana supone de alguna manera estar en contra de la doctrina católica (el matrimonio es un sacramento):

En los reinos y en las repúblicas bien ordenadas, había de ser limitado el tiempo de los matrimonios, y de tres en tres años se habían de deshacer, o confirmarse de nuevo, como cosas de arrendamiento; y no que hayan de durar toda la vida, con perpetuo dolor de entrambas partes (Cervantes 1994: 98).

No podemos dejar de recordar que, en Don Quijote, para Marcela el matrimonio es una carga.

\section{La casa como espacio hostil para las dos heroínas}

La falta de libertad y el matrimonio con un hombre mayor convierten hasta la propia casa en un espacio hostil para Lorenza, en el entremés El viejo celoso, y para Leonora, en El celoso extremeño.

La importancia del espacio circundante ha sido observada y explorada desde los albores de la literatura. Como subraya Antonio Carreño, «La consideración del espacio narrativo es un medio que ayuda a profundizar en la vida interior de los personajes. El espacio narra y se describe». (Carreño 2004: 1201).

\subsection{Lorenza}

Hondamente se graban en la memoria del lector las metáforas empleadas por Lorenza para nombrar al marido: «mi duelo, mi yugo y mi desesperación» (Cervantes 1994: 257). Inmediatamente después, la joven esposa no duda en gritar imprecaciones: «iQue fuera le vea yo desta vida a él y a quien con él me casó!» (Cervantes 1994: 257). Maldice el dinero del marido, y manifiesta su infelicidad: «iQue malditos sean sus dineros, fuera de las cruces, malditas sus joyas, malditas sus galas, y maldito todo cuanto me da y promete! ¿De qué me sirve a mí todo aquesto, si en mitad de la riqueza soy pobre, y en medio de la abundancia, con hambre?» (Cervantes 1994: 257). 
Lorenza aclara a su sobrina que no tuvo la libertad de escoger marido, y sugiere que sus padres la empujaron a casarse con el viejo, y sigue ensartando fuertes imprecaciones:

...diómele quien pudo, y yo, como muchacha, fui más presta al obedecer que al contradecir; pero si yo tuviera tanta experiencia destas cosas, antes me tarazara la lengua con los dientes que pronunciar aquel sí, que se pronuncia con dos letras y da que llorar dos mil años... (Cervantes 1994: 258).

La joven esposa parece haber perdido hasta la ilusión por las joyas y los vestidos, ya que no puede lucirlos, pero deja claro que aprecia a su marido por habérselos comprado, $\mathrm{y}$, de manera sorprendente y cómica, le desea salud, a pocos minutos después de haber deseado su muerte: «Que no quiero riquezas, señora Hortigosa; que me sobran las joyas, y me ponen en confusión las diferencias de colores de mis muchos vestidos; hasta eso no tengo que desear, que Dios le dé salud a Cañizares...» (Cervantes 1994: 260). La mujer utiliza unas sugestivas comparaciones al describir la generosidad del marido, en nítido contraste con las metáforas e imprecaciones anteriores: «más vestida me tiene que un palmito, y con más joyas que la vedriera de un platero rico» (Cervantes 1994: 260). No podemos dejar de destacar la incoherencia de esta mujer, incoherencia provocada por la presión de su vida cotidiana. Menciona la posibilidad del suicidio: «...estoy tan aburrida, que no me falta sino echarme una soga al cuello, por salir de tan mala vida» (Cervantes 1994: 261). Pero, en vez de suicidarse, buscará un amante joven, con ayuda de la vecina.

Su malestar se debe al hecho de vivir encerrada en casa: «Siete puertas hay antes que se llegue a mi aposento, fuera de la puerta de la calle, y todas se cierran con llave; y las llaves no me ha sido posible averiguar dónde las esconde de noche» (Cervantes 1994: 260).

El viejo marido enumera las medidas de precaución que ha tomado: «las ventanas, amén de estar con llave, las guarnecen rejas y celosías; las puertas jamás se abren; vecina no atraviesa mis umbrales» (Cervantes 1994: 263). Y tiene toda la razón, ya que al final, la desgracia le vendrá de la mano de una vecina.

El protagonista de este entremés se parece al de la novela ejemplar El celoso extremeño, ya que ambos están enfermos de celos, de manera que no toleran en sus casas ni animales machos, ni figuras masculinas en las tapicerías. Lorenza se lo cuenta a la vecina:

No me clavara él las ventanas, cerrara las puertas, visitara a todas horas la casa, desterrara della los gatos y los perros, solamente porque tienen nombre de varón; que, a trueco de que no hiciera esto, y otras cosas no vistas en materia de recato, yo le perdonara sus dádivas y mercedes. (Cervantes 1994: 260).

Sorprendentemente, el mismo viejo se da cuenta de sus errores, y los admite delante de otro hombre:

Señor compadre, señor compadre: el setentón que se casa con quince, o carece de entendimiento, o tiene gana de visitar el otro mundo lo más presto que le sea posible. Apenas me casé con doña Lorencica, pensando tener en ella compañía y regalo, y persona que se hallase en mi cabecera, y me cerrase los ojos al tiempo 
de mi muerte, cuando me embistieron una turbamulta de trabajos y desasosiegos; tenía casa, y busqué casar; estaba posado, y desposéme (Cervantes 1994: 262-3).

\subsection{Leonora}

En cuanto a Leonora, su historia empieza el día que se asoma a la ventana, y el viejo Carrizales pasa por la calle. La imagen de la adolescente asomada a la ventana posee gran fuerza dramática, ya que después de casarse, la misma adolescente «sólo los días que iba a misa veía las calles, y esto era tan de mañana que si no era al volver de la iglesia no había luz para mirallas» (Cervantes 1994: II 106). En unos días, el viejo Carrizales concierta el matrimonio con los padres de Leonora, y se casa con ella, no antes de dotarla «en veinte mil ducados: tal estaba de abrasado el pecho del celoso viejo» (Cervantes 1994: II 103). Pero el veneno de los celos no le concede tregua: «apenas dio el sí de esposo, cuando de golpe le embistió un tropel de rabiosos celos, y comenzó sin causa alguna a temblar y a tener mayores cuidados que jamás había tenido» (Cervantes 1994: II 103). Son interesantes aquí las figuras de estilo que emplea Cervantes para sugerir las vivencias de su héroe, la metáfora «pecho abrasado», y la personificación de los celos, que parecen un «tropel» que embiste, para sugerir la violencia de la zozobra del viejo.

Hay otros símiles y metáforas, que sugieren el amor de la protagonista, y a pesar de ser lugares comunes en la literatura de la época, aquí hacen su efecto, y resultan delicados. Leonora es una adolescente tan incauta, que se contenta con la miserable vida que lleva, y la considera normal:

La plata de las canas del viejo a los ojos de Leonora parecían cabellos de oro puro, porque el amor primero que las doncellas tienen, se les imprime en el alma como el sello en la cera. Su demasiada guarda le parecía advertido recato. Pensaba y creía que lo que ella pasaba, pasaban todas las recién casadas (Cervantes 1994: II 106).

Leonora se somete completamente a su marido, no se rebela nunca, no se resiste a nada de lo que el marido le imponga: «No se desmandaban sus pensamientos a salir de las paredes de su casa, ni su voluntad deseaba otra cosa más de aquella que la de su marido quería...» (Cervantes 1994: II 106).

Leonora es muy «tierna» (Cervantes 1994: II 104), y parece no importarle vivir en un rígido «encerramiento» (Cervantes 1994: II 105), pero la casa no es nada acogedora. El viejo no admite en su casa siquiera animales machos, lleva su prudencia al extremo de no permitir que entre en casa «algún animal que fuese varón» (Cervantes 1994: II 106). Cervantes destaca con ironía la paranoia del viejo: «A los ratones della jamás los persiguió gato, ni en ella se oyó ladrido de perro; todos eran del género femenino» (Cervantes 1994: II 106). No hay ninguna figura masculina, ni siquiera dibujada en las cortinas, tapices, $u$ otros adornos, Carrizales no recibe nunca a sus amigos en su casa, pero aun así vive sobresaltado:

De día pensaba, de noche no dormía; él era la ronda y centinela de su casa y el Argos de lo que bien quería; jamás entró hombre de la puerta adentro del patio. Con sus amigos negociaba en la calle. Las figuras de los paños que sus salas y cuadras adornaban, todas eran hembras, flores y boscajes (Cervantes 1994: II 106). 
Hasta los rincones más recónditos emanan decencia: «Toda su casa olía a honestidad, recogimiento y recato, aun hasta en las consejas que en las largas noches de invierno en la chimenea sus criadas contaban, por estar él presente, en ninguna, ningún género de lascivia se descubría» (Cervantes 1994: II 106). No es una casa para vivir, sino un templo de la moralidad. La vida no podrá ser engendrada, ni florecer en esta casa, donde falta el equilibrio entre los géneros.

A diferencia de Lorenza, Leonora no se queja, y parece no percibir su casa como un espacio hostil, pero, cuando consigue dormir al viejo gracias a un ungüento, «comenzó a dar brincos de contento» (Cervantes 1994: II 121), de manera que es indudable el malestar que le provoca aquella casa.

A duras penas consigue la aterrada Leonora untar al marido con el ungüento para dormir:

Temblando y pasito, y casi sin osar despedir el aliento de la boca, llegó Leonora a untar los pulsos del celoso marido, y asimismo le untó las ventanas de las narices, y cuando a ellas le llegó le parecía que se estremecía, y ella quedó mortal, pareciéndole que la había cogido en el hurto (Cervantes 1994: II 121).

Cuando Leonora está escuchando con sus criadas la música del joven Loaysa, y bailan, hay un momento en que creen que el viejo se ha despertado. Entonces están todos aterrorizados, el autor los compara con unas pobres palomas asustadas:

Quien ha visto banda de palomas estar comiendo en el campo sin miedo lo que ajenas manos sembraron, que al furioso estrépito de disparada escopeta se azora y levanta, y olvidada del pasto, confusa y atónita cruza por los aires, tal se imagine que quedó la banda y corro de las bailadoras, pasmadas y temerosas... (Cervantes 1994: II 126-7).

Pero a los demás personajes los impacta aquella casa espantosa. Una de sus criadas observa: «después que aquí nos emparedaron, ni aun el canto de los pajaros habemos oído» (Cervantes 1994: II 114). Otra había observado: «no tenemos ventanas a la calle para poder ver ni oír a nadie» (Cervantes 1994: II 114). El marido celoso, al construir la casa, «levantó las paredes de las azuteas de tal manera que el que entraba en la casa había de mirar al cielo por línea recta, sin que pudiesen ver otra cosa» (Cervantes 1994: II 104).

El negro eunuco se queja a su vez de estar «emparedado», al contarle a su amigo Loaysa que el amo «en saliendo por la mañana, cierra la puerta de la calle, y cuando vuelve hace lo mismo, dejándome emparedado entre dos puertas» (Cervantes 1994: II 109).

Loaysa declara a las criadas que está «condolido de su no vista clausura y de los ratos que en este estrecho género de vida se pierden» (Cervantes 1994: II 118).

El autor compara la casa con un monasterio, donde se guarda la honra del viejo Carrizales, asegurándonos que «no se vio monasterio tan cerrado, ni monjas más recogidas, ni manzanas de oro tan guardadas...» (Cervantes 1994: II 106).

Como hay tantas mujeres que dependen del jefe de familia, y están guardadas por un eunuco, Cervantes encuentra otro símil sugestivo: parece un «serrallo» (Cervantes 1994: II 120).

E viejo descubre la presencia del joven Loaysa en su casa, y se imagina que es amante de su esposa, pero, si en el primer momento quiere vengarse y lavar con 
sangre su honor, después habla con mucha sabiduría, con amargura y resignación, comprendiendo que él mismo tenía la culpa de su desgracia, por querer atajar a la naturaleza. La comparación con el gusano de seda es magnífica:

Pues quiero que así como yo fui extremado en lo que hice, así sea la venganza que tomaré, tomándola de mí mismo como del más culpado en este delito, que debiera considerar que mal podían estar ni compadecerse en uno los quince años desta muchacha con los casi ochenta míos. Yo fui el que como el gusano de seda me fabriqué la casa donde muriese, y a ti no te culpo, ¡oh niña mal aconsejada! (...), no te culpo digo, porque persuasiones de viejas taimadas, y requiebros de mozos enamorados fácilmente vencen y triunfan del poco ingenio que los pocos años encierran (Cervantes 1994: II 133).

\section{Referencias bibliográficas}

Canavaggio, Jean (1995): Historia de la literatura española. Tomo III, El siglo XVII. Barcelona: Ariel.

Carreño, Antonio (2004): “Cartografía de los espacios: la casa en «Don Quijote»”, en $P e$ regrinamente peregrinos. Actas del V Congreso Internacional de la Asociación de cervantistas (Lisboa, 1-5 de septiembre de 2003), II, Alicia Villar Lecumberri (ed.) Lisboa: Fundaçâo Calouste Gulbenkian, pp. 1201-1221.

Cervantes, Miguel de (2001): Don Quijote de la Mancha. I, II. Madrid: Alianza editorial.

Cervantes, Miguel de (1994): Entremeses. Madrid: Cátedra.

Cervantes, Miguel de (1992): Novelas ejemplares. I. Madrid: Cátedra.

Cervantes, Miguel de (1994): Novelas ejemplares. II. Madrid: Cátedra.

Díez de Revenga, Francisco Javier (2016): “Introducción”, en Mianda Cioba, Adolfo Rodríguez Posada, Melania Stancu, Silvia - Alexandra Ştefan (ed.), El retablo de la libertad. La actualidad del «Quijote». Bucarest: Institutul Cultural Român, pp. 9-15.

Díez Fernández, J. Ignacio (2004): “Tres discursos de mujeres”, en Peregrinamente peregrinos. Actas del V Congreso Internacional de la Asociación de cervantistas, II, (Lisboa, 1-5 de septiembre de 2003), II, Alicia Villar Lecumberri (ed.) Lisboa: Fundaçâo Calouste Gulbenkian, pp. 1255-1276.

Ivanovici, Víctor (2016): Itinerarios cervantinos. Quito: Casa de la Cultura Ecuatoriana Benjamín Carrión.

Rico, Francisco (2012): Tiempos del «Quijote». Barcelona: Acantilado.

Río, Ángel del (1982): Historia de la literatura española. Barcelona: Bruguera.

Unamuno, Miguel de (1992): Vida de Don Quijote y Sancho. Madrid: Cátedra. 